in $63 \%$ of children at 3 months, $41 \%$ at 12 months, and $29 \%$ at 24 months. Decreased appetite occurred in $52 \%$, stomachache in $40 \%$, depression in $30 \%$, headache in $26 \%$, insomnia $22 \%$, tachycardia $7 \%$, picking at skin $4 \%$, rocking $4 \%$, and nosebleeds $4 \%$. Growth was not slowed. Treatment was discontinued in $11 \%$ because of side effects. Comorbid disruptive behavior, anxiety, or mood disorders occurred in $26 \%$ and required concomitant psychotropic medications. (Ghuman JK, Ginsburg GS, Subramaniam G et al. Psychostimulants in preschool children with attention-deficit/hyperactivity disorder: clinical evidence from a developmental disorders institution. I Am Acad Child Adolesc Psychiatry May 2001;40:516-524). (Reprints: Dr J Ghuman, Director, Infant and Preschool Psychiatry Clinic, Kennedy Krieger Institute, 1750 East Fairmount Avenue, Baltimore, MN 21231).

COMMENT. Preschool children with ADHD and developmental disorders respond to psychostimulant medication but require close monitoring because of a relatively high incidence of side effects. A high rate of comorbid ODD and mood disorders may require concomitant or alternative psychotropic medications. A previous study, reviewed in Ped Neur Briefs April 2001;15:28-29, has demonstrated that parent training in behavior management techniques may accomplish a similar response to psychostimulants without the risk of side effects.

\title{
CARDIOVASCULAR SIDE EFFECTS OF PSYCHOSTIMULANTS
}

The short-term cardiovascular effects of methylphenidate (MPH) and Adderall (ADL) were examined in a clinic-based group of 195 youths, ages 4 to 17 years, treated at the University Hospitals of Cleveland, Case Western Reserve University. Resting pulse, and diastolic and systolic blood pressures were examined at baseline and after 1 week of placebo, and 3 dose levels of drug $(5,10$, and $15 \mathrm{mg}$ twice daily for MPH and once daily for ADL). Blood pressure and pulse were increased when measured 40 to 120 minutes after a dose of stimulant, but on average, changes were $<5 \mathrm{~mm} \mathrm{Hg}$ and $<5$ beats per minute. The effects were related to dose and of similar magnitude after MPH and ADL, but changes were not considered clinically meaningful. (Findling RL, Short EJ, Manos MJ. Short-term cardiovascular effects of methylphenidate and Adderall. LAm Acad Child Adolesc Psychiatry May 2001;40:525-529). (Reprints: Dr Findling, Director, Division of Child and Adolescent Psychiatry, University Hospitals of Cleveland, 11100 Euclid Avenue, Cleveland, $\mathrm{OH}$ 44106).

COMMENT. Short-term (1-3week) cardiovascular effects of methylphenidate and Adderall, as determined by changes in blood pressure and pulse rate, are minimal and not considered clinically significant. The authors suggest that routine cardiovascular monitoring is unnecessary during short-term treatment of ADHD with doses of $15 \mathrm{mg} /$ day or less of MPH or ADL None of the patients in this study had a history of hypertension, hypotension, or cardiovascular disease, and concomitant electrocardiograms were not obtained.

In our Clinic for Attention Deficit Disorders, Division of Neurology, Children's Memorial Hospital, an electrocardiogram and cardiac consultation is obtained if a heart murmur is detected at the initial evaluation or if a child complains of chest pain on exercise or palpitation during therapy. In a 10-yearold child with ADHD who was referred taking MPH-sustained release $(20 \mathrm{mg}$ tid, 60 $\mathrm{mg} /$ daily), a heart murmur was detected and the ECG showed a prolonged QT interval. The ECG returned to normal after reduction and withdrawal of MPH and remained normal with subsequent substitution of Adderall $5 \mathrm{mg}$ bid (Millichap JG, Yee M, and colleagues in Division of Cardiology; personal observations). 
Concurrent MPH and clonidine for ADHD. Concomitant MPH and clonidine is not generally recommended in practice, because of the reports of potential serious cardiovascular adverse reactions. If this combination therapy is considered essential, cardiac monitoring would seem to be mandatory. (Millichap JG. Attention Deficit Hyperactivity \& Learning Disorders, Chicago, PNB Publishers, Revised and Updated 2001).

\section{HEADACHE DISORDERS}

\section{CHARACTERIZATION OF CHRONIC DAILY HEADACHES}

Of 577 children ( 3 to 18 years of age) evaluated over 34 months in the multidisciplinary Headache Center at Cincinnati Children's Hospital Medical Center, 200 (35\%) were diagnosed with chronic daily headache $(\mathrm{CDH})$, having $>15$ headaches per month. Sixty-eight percent were girls, and $92 \%$ clinically had migraine headaches $(60 \%$ met the International Headache Society criteria for migraine). Nausea with or without vomiting occurred in $64 \%$, and photophobia and phonophobia in $60 \%$. CDH were divided into 3 subcategories: 1) $37 \%$ with frequent but not daily headaches; 2) $44 \%$ having episodic daily headaches; and 3) $20 \%$ having a continuous headache. All subcategories, including the continuous group, most closely match the criteria for migraine. (Hershey AD, Powers SW, Bentti A-L, LeCates S, deGrauw TJ. Characterization of chronic daily headaches in children in a multidisciplinary headache center. Neurology April (2 of 2) 2001;56:1032-1037). (Reprints: Dr AD Hershey, Headache Center, Division of Neurology, Children's Hospital Medical Center, Burnet Ave, Cincinnati, $\mathrm{OH} 45229$ ).

COMMENT. The nature of chronic daily headaches in children most closely match criteria for migraine, including the group with continous headaches. Many had analgesic rebound contributing to the $\mathrm{CDH}$, especially in the daily continuous group. The quality of life was impacted, as evidenced by school absences and functional disability. However, those with $\mathrm{CDH}$ appear to learn coping skills more effectively than patients with less frequent headaches, especially while at school.

\section{BENIGN INTRACRANIAL HYPERTENSION WITH NASAL STEROID}

A 13 year-old boy with Crohn's disease (in remission) was evaluated at the Department of Ophthalmology, University Hospital, Nottingham, UK, because of a 10 day history of head and back pain, intermittent blurring of vision, and squint. He had received 5 days of treatment with fluticasone propionate aqueous nasal spray ( $50 \mathrm{mg}$ daily) for hay fever. Bilateral papilledema was confirmed by fluorescein angiography, showing leakage of dye from the optic discs. There was a right sixth nerve palsy. CT was normal, and MRI excluded cavernous sinus thrombosis. CSF opening pressure was not measured; there were no cells, protein $0.1 \mathrm{~g} / 1$ and glucose $4.3 \mathrm{mmol} / 1$ (blood glucose $5.2 \mathrm{mmol} / 1$ ). Nasal spray was discontinued, and headaches and back pain, sixth nerve palsy, and papilledema resolved over a few weeks to months. This appears to be the first documented case of benign intracranial hypertension secondary to nasal fluticasone. (Bond DW, Charlton CPJ. Benign intracranial hypertension secondary to nasal fluticasone propionate. BMI 14 April 2001;322:897). (Respond: Drs Bond and Charlton, Department of Child Health, Department of Ophthalmology, Queen's Medical Center, University Hospital, Nottingham NG7 2UH, UK).

COMMENT. Corticosteroids may cause benign intracranial hypertension when administered by nasal spray, in addition to the systemic or topical routes. 